\title{
Epidemiological Situation of Measles in One of the Regions of the Republic of Kazakhstan
}

\author{
Fatima Meirkhankyzy Shaizadina, Bakhyt Nurgaliyevna Kosherova, \\ Alua Oralovna Omarova, Praskovya Mikhailovna Britskaya, \\ Nessipkul Oryntayevna Alysheva
}

Department of Epidemiology and Communal Hygiene, Karaganda State Medical University, 40, Gogol Street, 100008 Karaganda, Kazakhstan

\begin{abstract}
Objective: The aim of this study is to assessthe epidemiological situation of measles in one of the regions of the Republic of Kazakhstan. Materials and Methods: Retrospective study of measles morbidity during 2004-2014 was conducted. Statistical processing was carried out on the basis of the applied program of statistical processing "IBM SPSS Statistics 20." Results: The peak of incidence in one of the regions of Republic was registered in 2005, and by 2006, there has been a decrease in 81.1 times. Compared with the preceding year in 2014 there is an increase of incidence of measles in 1.1 times. Adults are sick with measles more often than children under 14. Until 2012, measles had often been registered among city dwellers; in 2013 and 2014, an increase of incidence of people who live in the country was noted. Index of timeliness of vaccination coverage against measles corresponded to normative indexes among babies under 1-year-old. A credible strong inverse correlation between measles morbidity and vaccination coverage ratio was found. Conclusion: The epidemiological situation of measles in the region remains tense.
\end{abstract}

Key words: Epidemic process, measles, morbidity

\section{INTRODUCTION}

$\mathrm{T}$ he relevance of the problem of measles in the world up to the middle of the $20^{\text {th }}$ century was defined by high levels of incidence in the population, its prevalence and high lethality among children. ${ }^{[1-3]}$

Although the introduction of vaccinal prevention of measles led to decrease in incidence, lethality and mortality in many countries of the world, acuteness of the problem was defined by the state of the epidemiological situation in each single territory.

Measles remains one of the main causes of death among children of early age around the world, even despite the existence of safe and efficient vaccine. The main danger of measles includes not so much in the course of the disease but in the high frequency and severity of complications..$^{[4,5]}$

Since 2011, there has been an adverse epidemiological situation of measles in the countries of the European region, where 34250 cases have been registered. In 2012, measles was registered in the territory of 47 subjects of the Russian Federation. ${ }^{[6]}$

In the Republic of Kazakhstan measles has been registered since the end of 2013. In 2014, the number of patients with measles in the Republic reached 321 and cases of measles were registered in all regions. In particular, in Almaty 51 people had measles, in Astana - 50, in East Kazakhstan region - 50, in South Kazakhstan region - 47, etc. In general, across the Republic, the morbidity rate per 100 thousand people in 2014 made 1.33, and in Almaty and Astana - 3.4 and 6.3 , respectively. ${ }^{[1,6-9]}$

Address for correspondence:

Alua Oralovna Omarova, Karaganda State Medical University, 40, Gogol street, 100008, Karaganda,

Kazakhstan, Email: alua_1912@mail.ru

Received: $23-11-2016$

Revised: $10-02-2017$

Accepted: 24-02-2017 
The analysis of the reasons of aggravation of the epidemic situation of measles in the Republic revealed that in certain territories there were defects in scheduling, poor control of organization and carrying out of immunoprophylactic measures, first of all in the groups of high risk of contagion, low level of training of health workers concerning the clinical picture, diagnostics and prophylaxis of measles. ${ }^{[1,8,11]}$

At the present stage, measles has stopped being a "children's" infection. Numerous studies have proved that measles in adults have features, which are not familiar for many practicing doctors. ${ }^{[6,10,11]}$ That leads to the late isolation and hospitalization of patients, as well as delayed treatment with subsequent development of heavy complications. Measles in adults is characterized by moderate or severe courses and the possibility of the development of meningoencephalitis, the outcome of which is favorable in case of well-timed diagnostics and adequate therapy. Students have measles more often that other groups, which proves the need of their vaccination as a matter of priority. ${ }^{[1,6,12,13]}$

The objective of our research was the assessment of epidemiological situation on measles in one of regions of the Republic of Kazakhstan.

\section{MATERIALS AND METHODS}

The object of the research was reporting and accounting documentation of Departments on Consumer Rights Protection of the Republic of Kazakhstan: "Report on certain infectious and parasitic diseases" form No. 1 and form No. 2; "Report on preventive vaccinations and vaccine flow" form No. 5; "Report on preventive vaccination coverage" form No. 6; preventive vaccination cards form No. 63; preventive vaccinations register form 064/y, case histories of hospitalized patients.

\section{Epidemiological research techniques}

Retrospective epidemiological analysis: Studying of longterm dynamics of incidence in 2004-2014, which will allow to reveal the structure, level, tendency, and forecast for the near future; studying of annual dynamics - evaluation of year-round, seasonal, and flare incidence; by epidemiological signs - risk groups and territories.

\section{Methods of statistical analysis}

The statistical analysis was carried out with the use of the application program of statistical processing "IBM SPSS Statistics 20," which provides a possibility of parametric and nonparametric analysis of data.

For the establishment of correlation, the parametric Pearson correlation coefficient was calculated. The significance level of the correlation coefficient was tested using Student's $t$-test.

\section{RESULTS AND DISCUSSION}

The analysis of the obtained data revealed that the peak of incidence of measles in one of the regions of the Republic was registered in 2005 (morbidity rate made 36.5 per 100,000 people); in 2006 a decrease in 81.1 times ( 0.45 per 100,000 people) was noted [Figure 1].

The morbidity rate in 2013 made 1.2, in $2014-1.4$ per 100,000 people, with an increase in 1.1 times. The theoretically predicted incidence in 2015 can make 3.7 per 100,000 people. The predicted size of incidence can be of any value ranging from $4.8 \%$ to $1.2 \%$.

During the analysis of age structure of the diseased, it was established that adults have measles more often than children under 14 [Figure 2]. During the period from 2004 to 2014 in this region, there were 263 cases of measles, where adult patients made 215 cases $(81.8 \%)$ and children under 14 made 48 ones $(18.3 \%)$.

It has been established that in 2005 the incidence among city dwellers made $86.8 \%$ of all revealed measles cases. The incidence among rural population made $13.1 \%$, which is by $6.6 \%$ less than in the city.

In 2006 and 2011, measles was registered only among the urban population. However, in 2013 and 2014 a rise in incidence among rural population was also observed.

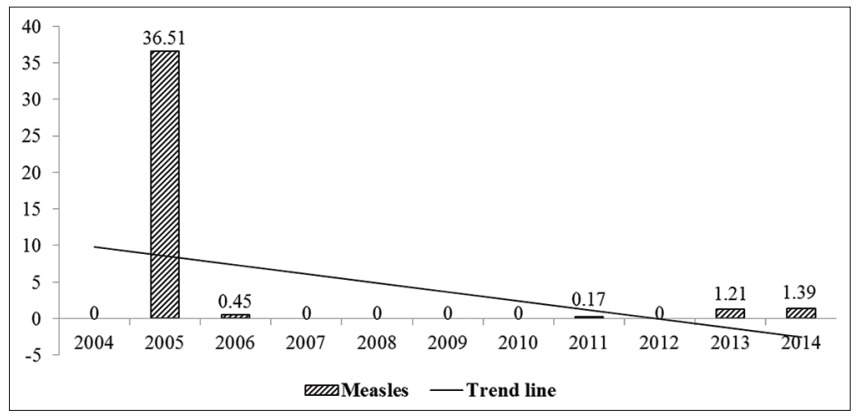

Figure 1: Long-term dynamics of measles morbidity for 2004-2014 (per 100,000 population)

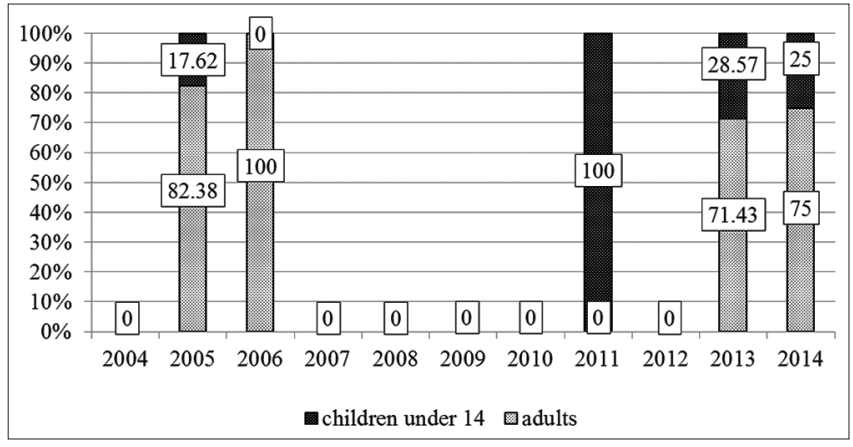

Figure 2: Age composition of measles patients (\%) 
Table 1: Number of people immunized against measles due to epidemic indications for 2009-2014

\begin{tabular}{|c|c|c|c|c|c|c|c|c|c|c|c|}
\hline \multirow[t]{3}{*}{ Years } & \multirow{3}{*}{$\begin{array}{c}\text { Total } \\
\text { vaccinated }\end{array}$} & \multirow{2}{*}{\multicolumn{2}{|c|}{$\begin{array}{c}\text { Including } \\
\text { children } \\
\text { (0-14 years old) }\end{array}$}} & \multirow{2}{*}{\multicolumn{2}{|c|}{$\begin{array}{c}\text { Including } \\
\text { teenagers } \\
(15-17 \text { years old })\end{array}$}} & \multicolumn{6}{|c|}{ Of them } \\
\hline & & & & & & \multicolumn{2}{|c|}{$\begin{array}{l}\text { Exposed in } \\
\text { the focuses of } \\
\text { disease }\end{array}$} & \multicolumn{2}{|c|}{ Migrants } & \multicolumn{2}{|c|}{$\begin{array}{c}\text { Additional } \\
\text { vaccinations }\end{array}$} \\
\hline & & $\begin{array}{l}\text { Against } \\
\text { measles }\end{array}$ & $\%$ & $\begin{array}{l}\text { Against } \\
\text { measles }\end{array}$ & $\%$ & $\begin{array}{l}\text { Against } \\
\text { measles }\end{array}$ & $\%$ & $\begin{array}{l}\text { Against } \\
\text { measles }\end{array}$ & $\%$ & $\begin{array}{l}\text { Against } \\
\text { measles }\end{array}$ & $\%$ \\
\hline 2009 & 697 & 468 & 67.14 & 0 & 0 & 683 & 97.99 & 2 & 0.29 & 12 & 1.72 \\
\hline 2010 & 113 & 9 & 7.96 & 0 & 0 & 35 & 30.97 & 7 & 6.19 & 71 & 62.83 \\
\hline 2011 & 9558 & 208 & 2.18 & 211 & 2.21 & 90 & 0.94 & 8 & 0.08 & 9460 & 98.97 \\
\hline 2012 & 286 & 56 & 19.58 & 0 & 0 & 103 & 36.01 & 1 & 0.35 & 182 & 63.64 \\
\hline 2013 & 2004 & 26 & 1.3 & 239 & 11.93 & 219 & 10.93 & 3 & 0.15 & 1782 & 88.92 \\
\hline 2014 & 3260 & 64 & 1.96 & 65 & 1.99 & 1065 & 32.67 & 1 & 0.03 & 2194 & 67.3 \\
\hline
\end{tabular}

The obtained data on vaccination coverage of the population demonstrate that from 2004 to 2014 the index of timeliness of vaccination coverage against measles of children under 1 year corresponded to normative indexes, and made more than $95 \%$.

However, in 2005, the percentage of coverage of children with the second measles vaccine was below normative indexes and made $90.86 \%$.

The strong inverse relation between an incidence of measles and percent of vaccination coverage was established, as the Pearson correlation coefficient made $r_{\mathrm{xy}}=-0.89$. Factor $t_{\text {calc }}=5.96$, which corresponds to probability of the faultless forecast of $P=0.01\left(t_{\text {crit }}=0.54\right.$, if $P=0.01$ and $\left.k=20\right)$.

According to the obtained data, it is possible to draw the following conclusion: The lower the percentage of measles vaccination coverage, the higher the incidence of this infection.

During research, a decrease in a number of children under 14 vaccinated against measles due to epidemic indications in 2014 compared to 2009 was observed in Table 1.

Analysis of the reasons of non-vaccination showed that in 2009 and 2010 a large share of all not vaccinated people was made by those having temporary contraindications $(60.7 \%$ and $46.9 \%$, respectively), and temporarily leaving (26.8\% and $45.4 \%$, respectively). In 2011, $60.6 \%$ of all people without vaccination were not vaccinated due to the lack of the vaccine and $27.3 \%$ had temporary contraindications. Among the immunized people, a large share was made by exposed ones in the focus of disease and by additionally vaccinated ones.

In 2009, exposed people in the focus of disease made $97.9 \%$ of all vaccinated due to epidemic indications. During the following years this number decreased due to the increase of the share of additionally vaccinated people, which in 2011 made $98.9 \%$ of all vaccinated due to epidemic indications.
During the last year, 3260 people were vaccinated due to epidemic indications, among them: $32.6 \%$ exposed in the focus of disease, $67.3 \%$, in addition, vaccinated and $0.03 \%$ migrants.

\section{CONCLUSION}

Thus, the analysis of long-term dynamics of measles morbidity in the people of this region has shown that the peak of incidence was registered in 2005. In 2014, an increase of morbidity rate was observed. An epidemiological feature of measles is a high prevalence of adult population. Incidence is registered both among the urban and rural population. The credible, strong inverse correlation between measles morbidity and percentage of vaccination coverage has been established.

\section{ACKNOWLEDGMENT}

The work has been made within the "Prediction of Risk of Incidence of Vaccine-Preventable Infections (Measles, Viral Hepatitis B) in the Republic of Kazakhstan" project, financed by Committee of Science of Ministry of Education and Science of the Republic of Kazakhstan, \#ГР0115РК00303.

\section{REFERENCES}

1. Bayesheva DA, Kosherova BN, Kuzgibekova SB. About the condition of infectious morbidity in the republic of Kazakhstan. Infectol J 2015;2:23.

2. Bektimirov TA. Advances of vaccinal prevention of measles, rubella and epidemic parotitis abroad. Vaccin 2006;4:4-5.

3. Jain A, Marshall J, Buikema A, Bancroft T, Kelly JP, Newschaffer CJ. Autism occurrence by MMR vaccine status among US children with older siblings with and without autism. JAMA 2015;313:1534-40. 
4. Abeyev AB, Aushakhmetova ZT. Molecular-genetic monitoring for measles as part of epidemiological surveillance in the city of Astana. Infectol J 2015;2:11-2.

5. Keegan R, Dabbagh A, Strebel PM, Cochi SL. Comparing measles with previous eradication programs: Enabling and constraining factors. J Infect Dis 2011;204 Suppl 1:S54-61.

6. Kim AA, Kolmogorova YA, Dauletova AY. Course of measles in adults. Infectol J 2015;2(7):56.

7. Begaidarova RK, Baituganova GZ, Starikov YG. Influence of planned immunization on epidemiological process of incidence of measles and rubella in Karaganda region. Med Ecol 2011;4:46.

8. Nazhdemenova AG, Kuatbayeva AM, Syzdykova MB. Epidemical situation for measles in the Republic of Kazakhstan at the present stage. Infectol J 2015;2:67-8.

9. Omarova AK, Bayesheva DA, Kenzhebayeva SK. Peculiarities of the course of measles in children at the present stage. Infectol J 2015;2:75.

10. Wagner AL, Zhang Y, Montgomery JP, Ding Y,
Carlson BF, Boulton ML. Timely measles vaccination in Tianjin, China: A cross-sectional study of immunization records and mothers. BMC Public Health 2014;14:888.

11. Sugerman DE, Barskey AE, Delea MG, Ortega-Sanche IR, Bi D, Ralston KJ, et al. Measles outbreak in a highly vaccinated population, San Diego, 2008: Role of the intentionally undervaccinated. Pediatrics 2010;125:747-55.

12. Elam-Evans LD, Yankey D, Singleton JA, Kolasa M; Centers for Disease Control and Prevention (CDC). National, state, and selected local area vaccination coverage among children aged 19-35 months - United States, 2013. MMWR Morb Mortal Wkly Rep 2014;63:741-8.

13. Levin A, Burgess C, Garrison LP Jr, Bauch C, Babigumira J, Simons E, et al. Global eradication of measles: An epidemiologic and economic evaluation. J Infect Dis 2011;204 Suppl 1:S98-106.

Source of Support: Nil. Conflict of Interest: None declared. 